\title{
REVIEW ON DOUBLE-LAYER WIDEBAND TRANSMITARRAY ANTENNA
}

\author{
Ms. A. A. Bellale \\ Department of Digital Communication \\ M.B.E.S. COE, Ambajogai, Maharashtra, India.
}

\begin{abstract}
Antennas are important electronic devices that are used for long distance communications such as wireless communications, remote sensing, broadcasting, and space exploration applications which also reduce the cost of hardware and space for setup. Transmitarray antenna is becoming a very popular and exciting concept due to its small size, light weight, beamsteering and high performance features. This paper presents a comprehensive analysis of different structures, new methodologies and designs adopted and experimented with transmitarray antenna.
\end{abstract}

Keywords - transmitarray, unit cell element, antenna beamsteering

\section{INTRODUCTION}

Transmitarray antennas are being very popular in now a day's giving high gain performance. These antennas are developed using the mixture of antenna array and optical theory concepts. High gain is achieved using antenna array theory which controls the interference of elements radiation. These consist of arrays of elements which cover hundreds or thousands of cells and by adjusting physical parameters of the cells; transmission coefficient along the surface can be controlled. Due to this the incident field coming from the feed can be converted to the desired radiated field. As a result, different parameters of the antenna such as beam pointing, beam shaping or polarization purity can be controlled and the performance of the system can be improved. These antennas works similar to the lens which allows incident wave to pass through with alteration of its direction of propagation as shown in fig 1(a). Structure design decides the direction of incident wave to be re-radiated. Based on meta material or microstrip patches and frequency selective surfaces the unit cells are designed [1]-[4]. Becoming a planar they are easily fits with other peripherals supporting higher degree of modularity to the system.

Apparently, it cannot be realized a wideband performance using dual-resonant square element in the four-layer transmitarray antenna. In order to improve the 1-dB gain of bandwidth the phase and magnitude on the aperture is controlled [5]. Usually transmitarray antenna composed of a thin transmitting surface and an illuminating feed source.

\author{
Prof. V. V. Yerigeri \\ Department of Digital Communication \\ M.B.E.S. COE, Ambajogai, Maharashtra, India.
}

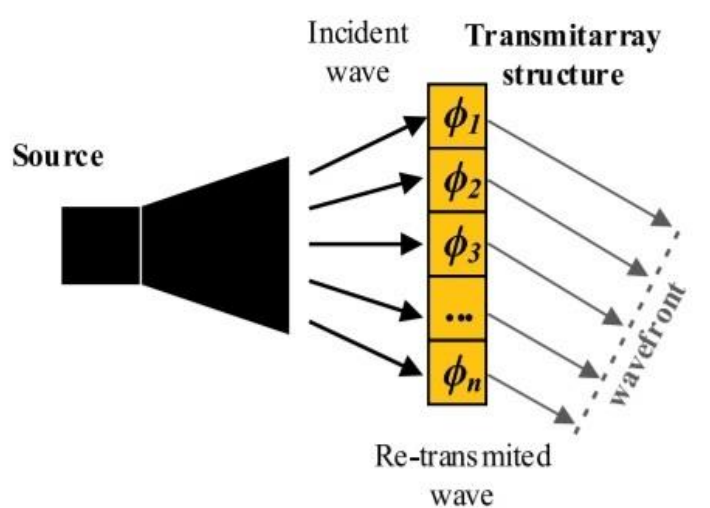

Fig. 1 Generic model of a transmitarray antenna

The remaining paper is organized as follows. Working principle of transmitarray antenna, advantage of transmitarray antenna according to shape and size are stated and also and research oriented studies are summarized in this paper. Proposed designs of unit cell element of transmitarray and beamsteeering with a transmitarray are discussed in section II. Concluding remarks are given in section III.

\section{TRASMITARRAY DESIGN}

There are different techniques to design transmitarray antennas, they are as:

(a) Multi-layer frequency selective surface (M-FSS),

(b) Receiver-transmitter design, and

(c) Metamaterial/transformation approach

This section focuses on different unit cell design approaches with different structures and parameters, as well as on beamsteering for the required specification.

\section{B. Unitcell Design}

The parametric study of the unit cell element is performed to obtain the required characteristics of the array elements. We can control the phase of each array element individually by varying its dimension or by varying metamaterial configuration. The objective of transmitarray unit cell design is to have $360^{\circ}$ phase control and close to $0 \mathrm{~dB}$ magnitude transmission coefficient at all required phase states. The phase 


\section{International Journal of Engineering Applied Sciences and Technology, 2020 Vol. 4, Issue 11, ISSN No. 2455-2143, Pages 484-488 \\ Published Online March 2020 in IJEAST (http://www.ijeast.com)}

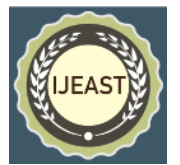

shift can be obtained with control of phase delay realized by each individual elements of the transmitarray. The impedance observed by the incident wave specifies required phase compensation value. This impedance gets changes with geometry of the cell.

To improve the bandwidth of transmitarray antennas the new design techniques are adopted and it is done by controlling transmission phase range of the elements. These techniques are corroborated by the production and testing of the two quad-layer transmitarray antennas at Ku-band. The maximum transmission phase range can be calculated using the number of layers, substrate permittivity, and the separations between layers. Most of researches had implemented these unit cells using a multilayer approach to achieve specific goals with specific structure and design. In [6], two degrees of freedom is used to design double-layer wideband transmitarray element which realizes 360-degree phase shift range. They had achieved a gain of $29.4 \mathrm{dBi}$ with aperture efficiency of $40 \%$ attained at $21 \mathrm{GHz}$ using simulation. With this double-layer structure concept, the proposed transmitarray antenna makes easy of design complexity and also sorts out the problems of thickness, mass, and cost. In [7] the unit cell element is implemented using a four-layer double split ring slot structure and tested at $\mathrm{Ku}-$ band to gain high performance and efficiency in transmitarray antenna.

In [8] and [9], the authors have presented the structures of transmitarray which composed of staked layers of periodically printed sub-wavelength metallic resonators with embedded microwave varactors. These resonant characteristics of the unit-cell are modified controlled by adjusting the varactor diode, in fact, the associated phase-delay between the first and the last layer of the transmitarray. As a result, a single transmitarray element is being adjusted according to the associated effective refractive index. In the same way, if a progressive phase between adjacent elements is applied through organized row in order to perform beamsteering, the metamaterial shows a smooth change of index of refraction, when seen as a whole.

A full transmission phase range of $360^{\circ}$ is realised for a transmission magnitude equal to or better than $-4.2 \mathrm{~dB}$ using spiral-dipole elements with triple-layer transmitarray antenna at X-band in [10] to attain preferred radiation pattern. An advantage of low transmission loss and less sensitivity to the incidence angle of the electric field has been followed with high-efficiency transmitarray device using four-layer slot structure in [7]. The array element with three thin metallic layers having an air gap in between them is designed for a novel wideband, high-efficient and linear-polarized transmitarray antenna in [10]. A double layer structure is found to be more advantageous over a multi-layer structure as of easy processing and cheaper in cost as compare to the multi-layer structure. Here transmission magnitude and phase shift are the two most essential concerns to be considered while designing double-layer structure. Initially, phase shifting range in the aperture fields, a phase tuning range of $360^{\circ}$ is prerequisite for an element to be suitable for large array to design a unit cell. Next, the transmission magnitude has to maintained up to $1(0 \mathrm{~dB})$ to guarantee a high aperture efficiency. Most of research papers are tried to resolve insufficiency of transmission magnitude and phase [11-17] in their research. The [17], develops a unit cell element using malta crosses with metal vias. The 300 -degree phase shift is realized with developed element by augmenting the transmission magnitude with measured 1-dB gain bandwidth of $5.9 \%$ and aperture efficiency of $40 \%$ an accepted radiation characteristics are simulated and measured.

In [18], authors have adopted a very simple and reliable approach to design and analysis of multiple layer structures that can be used as phase shifting cells in transmitarray antennas. A comparison of compared two, three, and four layers approach are studied together with the different types of inductive and capacitive elements. The results are analysed with respect to variations of spacing between the layers of the element, sensitivity to incidence angle variations and a frequency response. The transmission phase range of $360^{\circ}$ is specified with an array element of $-3 \mathrm{~dB}$ bandwidth of more than $20 \%$ is reached for cells covering. The performance calculated in absolutely independent of the specific geometry of element.

In [19], the design of a linearly polarized transmitarray antenna for backhauling applications at V-band is presented. They have used a three metal layer standard PCB, an ad hoc focal source, and a radome layer to design a planar circularshape array with 1264 unit-cells. In [11] authors have implemented a circular transmitarray with a diameter $100 \mathrm{~mm}$ to measure gain of $32.5 \mathrm{dBi}$ at $61.5 \mathrm{GHz}$ with aperture efficiency of $42.7 \%$ and a $1-\mathrm{dB}$ gain fractional bandwidth of $15.4 \%(57-66.5 \mathrm{GHz})$.

Multilayer design is also one of the best ways to configure required specification for the antenna. This approach leads to the complex design structure and also increases the cost of fabrication as compared to other transmitarray antennas. In [20] the substrate material, the space between layers, shape of unit element and the layer count are used to calculate the relation between magnitude and phase of an element in a multilayer frequency selective surface (M-FSS). Transmission coefficient of multilayer conductors separated by dielectric material is analysed and stated in this article.

\section{B. Beamsteeering with a Transmitarray:}

Beamsteering is a way to dynamically alter beam pattern by changing the signal phase in real time independent of antenna elements or the hardware. There are many ways to design and structure the transmitarray antenna based on antenna beamsteering. This technique includes the use of different substrate materials, element designs and implementation approaches. For beamsteering of antenna radiation one condition must be followed. The tunabe transmission phase up to 360 must be followed in transmitarray element by keeping desirable magnitude as it is. 


\section{International Journal of Engineering Applied Sciences and Technology, 2020 \\ Vol. 4, Issue 11, ISSN No. 2455-2143, Pages 484-488 \\ Published Online March 2020 in IJEAST (http://www.ijeast.com)}

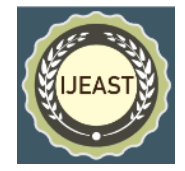

The phase shift is obtained by gaining a control over phase delay generated by every transmitarray unit cell.

In [21] researchers presented a new 2D-beamsteering antenna technique. This technique introduces an electronically controlled transmitarray which is tied to a conventional horn or an array patch antenna. With this coupling antenna can steer the main lobe of the original pattern in both elevation and azimuth planes, having ranges up to $30^{\circ}$ and $30^{\circ}$ respectively.

In [22] an applications of channel sounding and massive multiple-input multiple-output (M-MIMO) systems are presented by implementing a beam-steering transmitarray antenna operating in V-band $(57-64 \mathrm{GHz})$. These systems composed of a transmitarray panel which is made of 8-phase state unit-cells and illuminated by a $2 \times 2$ element focal plane array. For antenna beam scanning focal plane array in the focal plane is displaced.

The [23] proposes, configurable transmitarray for beamsteering which consists of a set of patch antennas. These antennas are mounted on both sides of the array structure. Then these array elements are coupled with an electronically tunable phase-shifter this makes the design differ from other approaches. in transmission line technology, the phase-shifter is implemented. This phase shifter consists of a microstrip directional coupler terminated with reflective LC circuits. The varactor diode controls the capacitance (C) of this LC circuits. The design in [12] develops an integrated leaky-wave which feeds a spatially distribute power in a reconfigurable transmitarray aperture in a low-profile manner instead individual unit cell phase control using varactor diodes permits full-space pencil-beamsteering. Full-space (both azimuth and elevation) beamsteering was observed at angles up to $45^{\circ}$ off broadside with a total efficiency for all scan angles on the order of $25 \%-35 \%$ with a $6 \times 6$ element array. The transmission phase of every 2-D transmitarray unit cell decides the output steering direction.

The paper [24] states a reconfigurable unit-cell for transmitarray antennas. This antenna consists of a 2-bit phase resolution in Ka-band parameterized with unit-cell of $5.1 \times 5.1 \times 1.3 \mathrm{~mm}^{3}$ size. The structure constructed on a dielectric stack-up having a three dielectric substrates, two bonding films and six metal layers with it. The simulation is implemented and compared with a 1-bit phase quantization obtaining a gain of $22.9 \mathrm{dBi}$, an aperture efficiency of $32.3 \%$, and a side-lobe level equal to $-18.1 \mathrm{~dB}$ at broadside at $29 \mathrm{GHz}$.

Lau and Hum in [25]-[28] configured various models of transmitarray elements which can be controlled electronically. In [26] they have focused on antenna beamsteering, and then modified in [27]. The unit cell of transmitarray composed of two microstrip patches on either side of a ground plane is engaged to a small slot aperture. Each patch is divided into two halves and a little space in between, and varactor diodes introduced to attach the two half's, while another varactor diode is placed at the center of the slot, linking the two sides of the slot. Three coupled tunable resonators is configured using these all parts together providing a variable phase-shift over $360^{\circ}$ with $3 \mathrm{~dB}$ of insertion losses, as stated in [28]. On the other hand, the losses are slightly increased to $4.8 \mathrm{~dB}$ by keeping bandwidth as it is, when the projected element is made up of a $6 \times 6$ array and the biasing network to control the varactors are consisted, as shown in Fig.2 [28]. However, the proposed prototype gains $\pm 25^{0}$ of electronically controlled beam scanning, in azimuth and elevation planes autonomously, having broadside directivity of $20.8 \mathrm{dBi}$. [29]

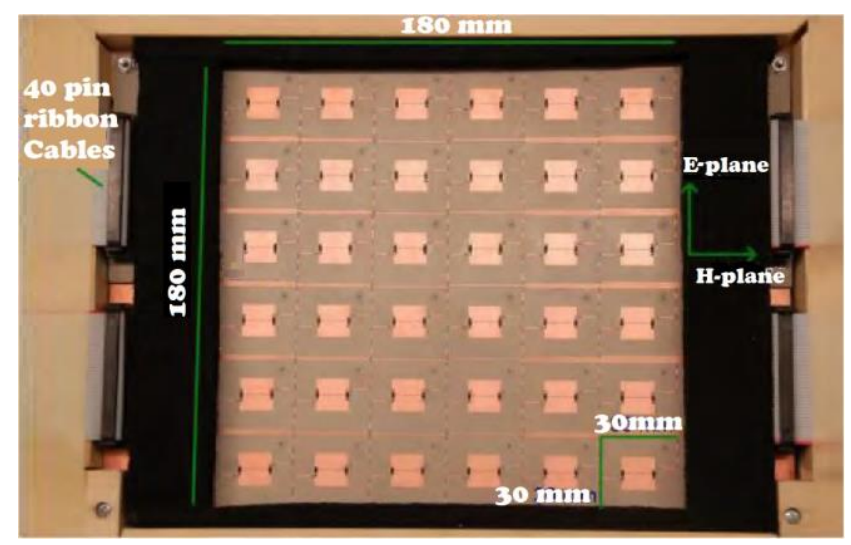

Fig. 2 Transmitarray Prototype [27]

In [30] the authors have implemented and characterized an artificial gradient-index metamaterial. This is done by designing a fishnet structure on a liquid crystal substrate providing a continuous tuning of each column of the array. Measurements conducted at $27.5 \mathrm{GHz}$ by practically validating transmitarray. A beam steering angular range limited to $\pm 5^{0}$ was obtained by varying, in a gradient manner, the bias of each array column. The fig. 3 shows typical structure of multilayer enhancement with the yielded angular range specified by authors.

Notably [9] depicts a complete classification of a metamaterial transmitarray composed by the unit cell was performed. They have been realized an antenna steering using a type of active metamaterial with tunable refractive index experimentally. To serve as feeding source, an array of microstrip patch antennas was also prototyped. The device implemented with a stacked layer structure and proposed with an angular steering range of $\pm 30^{\circ}$ in azimuth verified under experiments at $4.7 \mathrm{GHz}$. Various samples of radiation pattern are also experimented and shown by the researchers in their article. 


\section{International Journal of Engineering Applied Sciences and Technology, 2020 \\ Vol. 4, Issue 11, ISSN No. 2455-2143, Pages 484-488 \\ Published Online March 2020 in IJEAST (http://www.ijeast.com)}

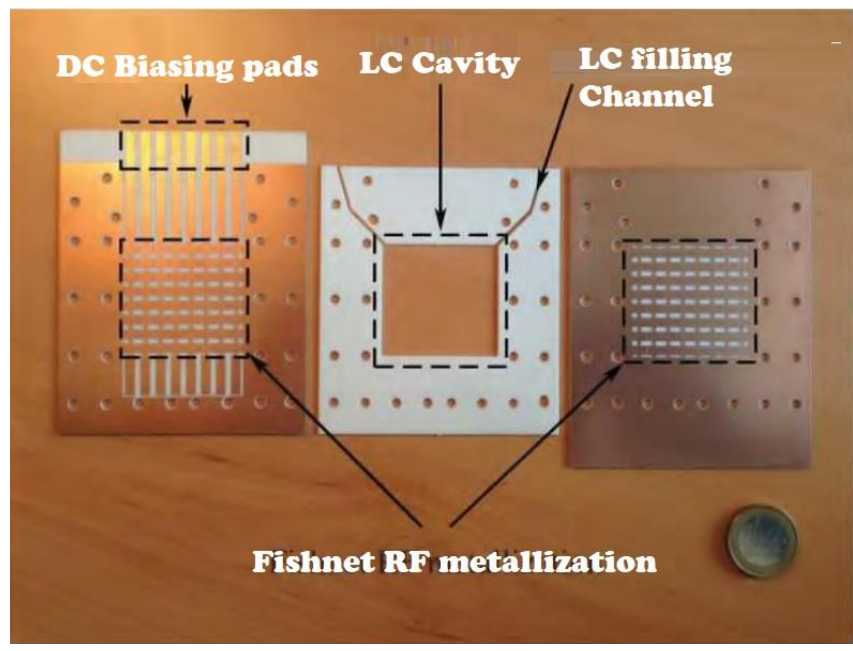

Fig. 3 Prototype of a single opened fishnet unit-cell layer [30]

Some examples have been presented in [31]-[32] by reconfiguring transmitarray of FSS for antenna beamsteering. In most of sense varactor diodes are used to electronically control the capacitance of the equivalent LC circuit which characterizes the resonant unit-cell design, as presented by Russo et. al. (2009,2010 and 2014) in [31]-[33]

\section{CONCLUSION}

This paper gives a comprehensive study report on different facts, design structures, design shapes, metamaterial used and antenna beamsteering while fabricating transmitarray antenna. Basic differences are analyzed according to different shapes used in fabrication. In most of the research papers a double layer approach is adopted for simplifying structure and design of antenna producing low cost as compared to multilayer antenna. Also review on antenna beamsteering, with polarization control and combining both features in transmitarray was also studied. Several researches are compared and stated in this survey. This review paper shows that transmitarray antennas can be seen as a most popular way to develop antenna instead of using traditional antennas having advantages in beamsteering, overcoming some limitations also.

\section{REFERENCE}

[1] Capolino F.(2009) Applications of Metamaterials. Boca Raton, FL, USA: CRC Press.

[2] Balanis C. (2012), Advanced Engineering Electromagnetics (Coursesmart). Hoboken, NJ, USA: Wiley.

[3] Vardaxoglou J. C. (1997), Frequency Selective Surfaces-Analysis \& Design. Taunton, U.K.: Research Studies Press.
[4] Munk B. A.(2005) Frequency Selective Surfaces: Theory and Design. Hoboken, NJ, USA: Wiley.

[5] Abdelrahman A. H.; Nayeri P.; Elsherbeni A. Z. and Yang F. (2015), "Bandwidth improvement methods of transmitarray antennas," IEEE Trans. Antennas Propag., vol. 63, no. 7, pp. 2946-2954.

[6] Yi X.; Su T.; Li X.; Wu B. and Yang L. (2019), "A Double-Layer Wideband Transmitarray Antenna Using Two Degrees of Freedom Elements Around $20 \mathrm{GHz}$," in IEEE Transactions on Antennas and Propagation, vol. 67, no. 4, pp. 2798-2802.

[7] Liu G.; Wang H.; Jiang J.; Xue F. and Yi M. (2015), "A High-Efficiency Transmitarray Antenna Using Double Split Ring Slot Elements," in IEEE Antennas and Wireless Propagation Letters, vol. 14, pp. 1415-1418.

[8] Sun Y.; Li Z.; Zhu W.; Ji Z., and Wang Q. (2012), ' New steerable antenna with controllable metamaterial,', in Proc. 9th Eur. Radar Conf. (EuMC), pp. 610-613.

[9] Jiang T., Wang Z., Li D., Pan J., Zhang B., Huangfu J., Salamin Y., Li C., and Ran L. (2012), 'Low-DC voltagecontrolled steering-antenna radome utilizing tunable active metamaterial," IEEE Trans. Microw. Theory Techn., vol. 60, no. 1, pp. 170-178.

[10] Rahmati B., Hassani H. R. (2015), "high-efficient wideband slot transmitarray antenna," IEEE Trans. Antennas Propag., vol. 63, no. 11, pp. 5149-5155.

[11] Rahmati B, Hassani H. R. (2015), "low-profile slot transmitarray antenna," IEEE Trans. Antennas Propag., vol.63,no.1,pp. 178-180.

[12] Nicholls J. G., Hum S. V. (2016), “full-space electronic beam-steering transmitarray with integrated leaky-wave feed," IEEE Trans. Antennas Propag., vol.64, no. 4, pp. 1473-1481.

[13] Nematollahi H., Laurin J. (2015), “design of broadband transmitarray unit cells with comparative study of different numbers of layers," IEEE Trans. Antennas Propag.,vol.63,no.8,pp. 3410-3422.

[14] Tian C., Jiao Y. C., Zhao Guang (2017), “circularly polarized transmitarray antenna using low-profile duallinearly polarized elements," IEEE Antennas Wireless Propag. Lett., vol. 16, pp. 465-468.

[15] Lau J. Y., Hum S. V. (2011), "analysis and characterization of a multipole reconfigurable transmitarray element," IEEE Trans. Antennas Propag., vol. 59, no. 1, pp. 70-79.

[16]Plaza E. G., Leon G., Loredo S. (2017), “An ultrathin 2bit near-field transmitarray lens," IEEE Antennas Wireless Propag. Lett., vol. 16, pp. 1784-1787.

[17]An Wenxing, Xu Shenheng (2016), “a double-layer transmitarray antenna using malta crosses with vias," IEEE Trans. Antennas Propag.,vol.64,no.3,pp. 11201125 .

[18] Abdelrahman A. H., Elsherbeni A. Z., and Yang F. (2014), "High-gain and broadband transmitarray antenna 


\section{International Journal of Engineering Applied Sciences and Technology, 2020 \\ Vol. 4, Issue 11, ISSN No. 2455-2143, Pages 484-488 \\ Published Online March 2020 in IJEAST (http://www.ijeast.com)}

using triple-layer spiral dipole elements," IEEE Antennas Wireless Propag. Lett., vol. 13, pp. 1288-1291.

[19] Jouanlanne C. Clemente A., Huchard M., Keignart J. (2017), "Wideband Linearly Polarized Transmitarray Antenna for $60 \mathrm{GHz}$ Backhauling," in IEEE Transactions on Antennas and Propagation, vol. 65, no. 3, pp. 14401445.

[20]Abdelrahman A. H., Elsherbeni A. Z., and Yang F., (2014) "Transmission phase limit of multilayer frequency selective surfaces for transmitarray designs," IEEE Trans. Antennas Propag., vol. 62, no. 2, pp. 690-697.

[21]Reis J., Al-Daher Z., Copner N., Hammoudeh A., Caldeirinha R. and Fernandes T. (2014), "Twodimensional transmitarray beamsteering using stacked tunable metamaterials," 2014 Loughborough Antennas and Propagation Conference (LAPC), Loughborough, pp. 495-499.

[22]T. Pham, F. Gallée and R. Sauleau, "A Beam-Steering Transmitarray Antenna for 5G MIMO Channel Sounding in V-band," 2019 49th European Microwave Conference (EuMC), Paris, France, 2019, pp. 630-633.

[23] Padilla P., Muñoz-Acevedo A., Sierra-Castaner M., and Sierra-Perez M. (2010), "Electronically reconfigurable transmitarray at $\mathrm{Ku}$ band for microwave applications,', IEEE Trans. Antennas Propag., vol. 58, no. 8, pp. 25712579.

[24]Diaby et al. (2017), "Design of a 2-bit unit-cell for electronically reconfigurable transmitarrays at Ka-band" European Radar Conference (EURAD), Nuremberg, 2017, pp. 473-476.

[25]Lau J. Y. (2012), “Reconfigurable transmitarray antennas,' Ph.D. dissertation, Dept. Elect. Comput. Eng., Univ. Toronto, Toronto, ON, Canada.

[26] Lau J. Y. and Hum S. V. (2011), “Analysis and characterization of a multipole reconfigurable transmitarray element,' IEEE Trans. Antennas Propag., vol. 59, no. 1 , pp. 70-79.

[27] Lau J. Y. and Hum S. V. (2010), “A planar reconfigurable aperture with lens and reflect array modes of operation,' 'IEEETrans.Microw.TheoryTechn., vol. 58, no. 12 , pp. $3547-3555$.

[28]Lau J. Y. and Hum S. V. (2012), "A wideband reconfigurable transmitarray element," IEEE Trans. Antennas Propag., vol. 60, no. 3, pp. 1303-1311.

[29] Lauand J. Y., Hum S. V. (2012), "Reconfigurable transmitarray design approaches for beamforming applications,", IEEE Trans. Antennas Propag., vol. 60, no. 12, pp. 5679-5689.

[30]Reis J. R., Vala M. and Caldeirinha R. F. S. (2019), "Review Paper on Transmitarray Antennas," in IEEE Access, vol. 7, pp. 94171-94188.

[31] Maasch M., Roig M., Damm C., and Jakoby R. (2014), "Voltage-tunable artificial gradient-index lens based on a liquid crystal loaded fishnet metamaterial,' IEEE Antennas Wireless Propag. Lett., vol. 13, pp. 1581-1584.
[32] Russo I., Gaetano D., Boccia L., Amendola G., and Massa G. Di (2009), "Investigation on the transmission beamsteering capabilities of tunable impedancesurfaces,', in Proc. Eur. Microw. Conf. (EuMC), pp. 1033-1036.

[33] Russo I., Gaetano D., Boccia L., Amendola G., and Massa G. Di (2010), “Tunable pass-band FSS for beam steering applications,' in Proc. 4th Eur. Conf. Antennas Propag. (EuCAP), pp. 1-4.

[34]Boccia L., Russo I., Amendola G., and Massa G. D. (2012), "Multilayerantennafilter antenna for beamsteering transmit-array applications," IEEE Trans. Microw. Theory Techn., vol. 60, no. 7, pp. 2287-2300.

[35]Pan W., Huang C., Chen P., Pu M., Ma X., and Luo X. (2013), "A beam steering horn antenna using active frequency selective surface,' IEEE Trans. Antennas Propag., vol. 61, no. 12, pp. 6218-6223.

[36] Sazegar M., Zheng Y., Kohler C., Maune H., Nikfalazar M., Binder J. R., and Jakoby R. (2012), “Beam steering transmitarray using tunable frequency selective surface with integrated ferroelectric varactors,' IEEE Trans. Antennas Propag., vol. 60, no. 12, pp. 5690-5699. 